\title{
CORTICOMUSCULAR COHERENCE IN PRE-TREATMENT CANCER-RELATED FATIGUE vS CHRONIC FATIGUE SYNDROME
}

Ciara M. O'Higgins ${ }^{* 1,2,3}$, Stefan Dukic1', Brenda O'Connor ${ }^{3,4}$, Anna Rice $^{2}$, Marjja Markicevic ${ }^{1}$, Declan Walsh ${ }^{2,3,4,5}$ Richard B. Reilly',2,

1.School of Medicine, Trinity College Dublin, 2.Trinity Centre for Bioengineering, Trinity College Dublin, 3. Department of Palliative Medicine, Our Lady's Hospice, Dublin 4. School of Medicine \& Medical Sciences, University College Dublin 5. Levine Cancer Institute, Charlotte, North Carolina.

\section{BACKGROUND}

1. Fatigue is prevalent, highly debilitating \& underdiagnosed in Cancer and Chronic Fatigue Syndrome (CFS)

2. The aetiology is poorly understood

3. No gold standard objective measure

4. Studies have shown a dissociation between brain and muscle signals during voluntary muscle fatigue

\section{OBJECTIVES:}

> To evaluate the effect of muscle fatigue on corticomuscular coherence by determining EEG-EMG coherence during a motor task

> We hypothesized that corticomuscular coherence in ßeta-band frequency would be weakened and decrease with fatigue in CRF \& CFS compared to healthy controls $(\mathrm{HC})$

\section{METHODS}

Participants:

12 newly diagnosed, pre-treatment, NonSmall Cell Lung Cancer (CRF)

12 Chronic Fatigue Syndrome (CFS)

12 Healthy Controls $(\mathrm{HC})$

\section{Data Collection Measures}

- Brief Fatigue Inventory

- EEG \& EMG were simultaneously recorded during a motor fatigue task by a hand-held dynamometer (Figure 1)

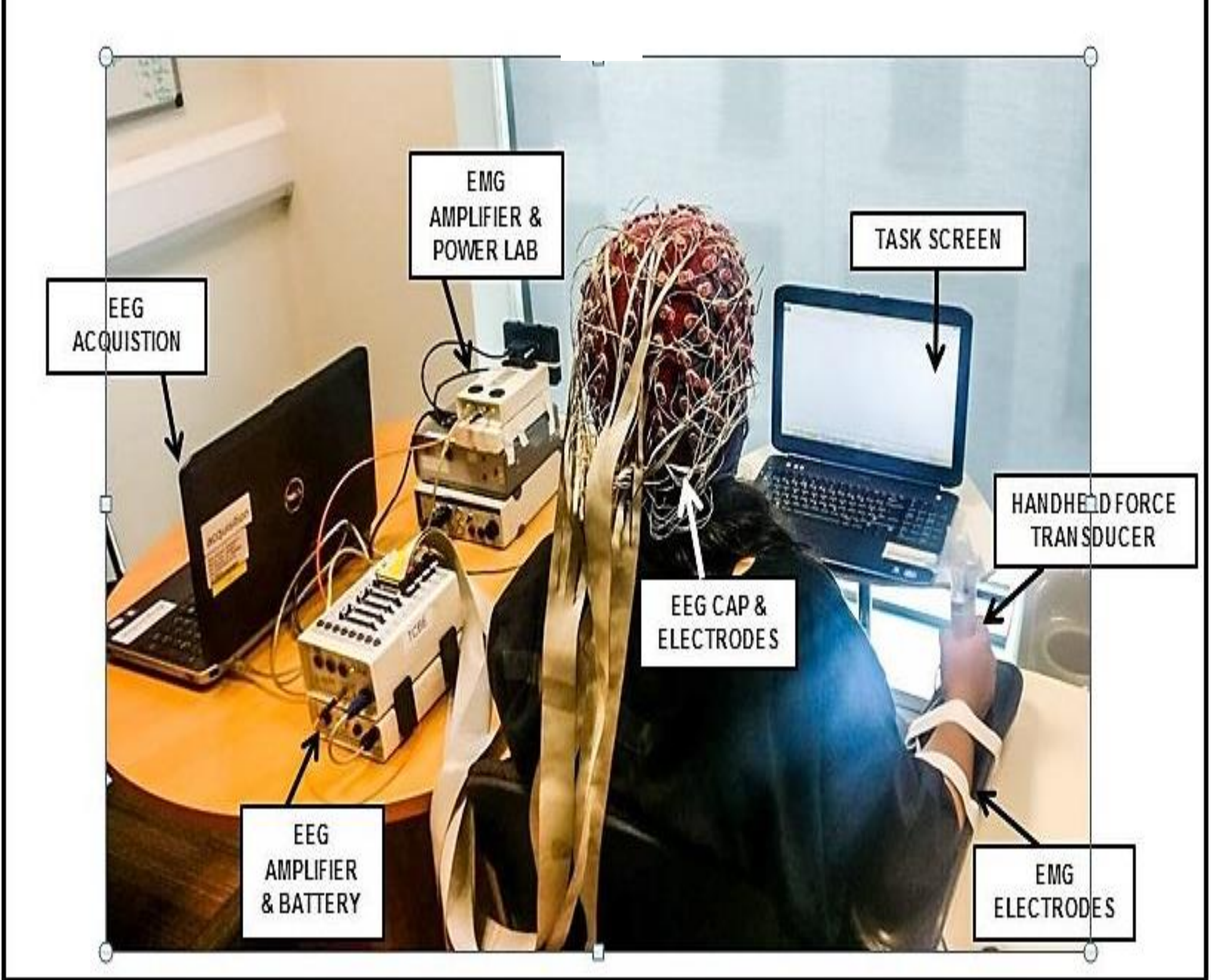

Figure 1: The participant is facing the task screen with their forearm restrained. The participant grips the provided by the task screen. EFG and EMG an intheonly rocond during the bask

\begin{tabular}{|c|c|c|c|c|c|}
\hline \multicolumn{6}{|l|}{ RESULTS } \\
\hline Group & Gender & $\begin{array}{c}\text { Age } \\
\text { (years) }\end{array}$ & $\begin{array}{l}\text { Brief Fatigue } \\
\text { Inventory }\end{array}$ & $\begin{array}{l}\text { Endurance } \\
\text { Time (s) }\end{array}$ & $\begin{array}{c}\text { Maximum } \\
\text { Voluntary } \\
\text { Contraction(N) }\end{array}$ \\
\hline CRF & $\begin{array}{c}\text { Female: } 6 \\
\text { Male: } 6\end{array}$ & $65 \pm 11$ & $3.2 \pm 2$ & $201 \pm 165$ & $305 \pm 127$ \\
\hline CFS & $\begin{array}{c}\text { Female: } 8 \\
\text { Male: } 4\end{array}$ & $49 \pm 11$ & $6.5 \pm 1^{* *}$ & $291 \pm 165$ & $237 \pm 65^{*}$ \\
\hline $\mathrm{HC}$ & $\begin{array}{c}\text { Female: } 5 \\
\text { Male: } 7\end{array}$ & $50 \pm 13$ & $2.3 \pm 2$ & $512 \pm 417$ & $351 \pm 152$ \\
\hline
\end{tabular}

[Table 1: Demographic details and Mean of AGE, BFI, ET and MVC scores. $\left.\left({ }^{*} \mathrm{P}<0.05,{ }^{* *} \mathrm{P}<0.001\right)\right]$

CFS significantly higher $\mathrm{BFI}$ mean fatigue $(6.5 \vee 3.2, \mathrm{p}=\mathbf{0 . 0 0 5})$ compared to CRF (Table 1)

CRF and CFS weaker MVC and earlier exhaustion than HC (Table 1)

EMG power (but not EEG) increased in both muscle groups in severe fatigue for $\mathrm{HC}$ and CRF but not CFS

Coherence at lower ßeta-band (15-25 Hz) significantly decreased in severe compared to mild fatigue (Figure 2) in FCU for HC \& FCR for CRF

$>$ Coherence at the broad ßeta-band $(15-35 \mathrm{~Hz})$ no significant change

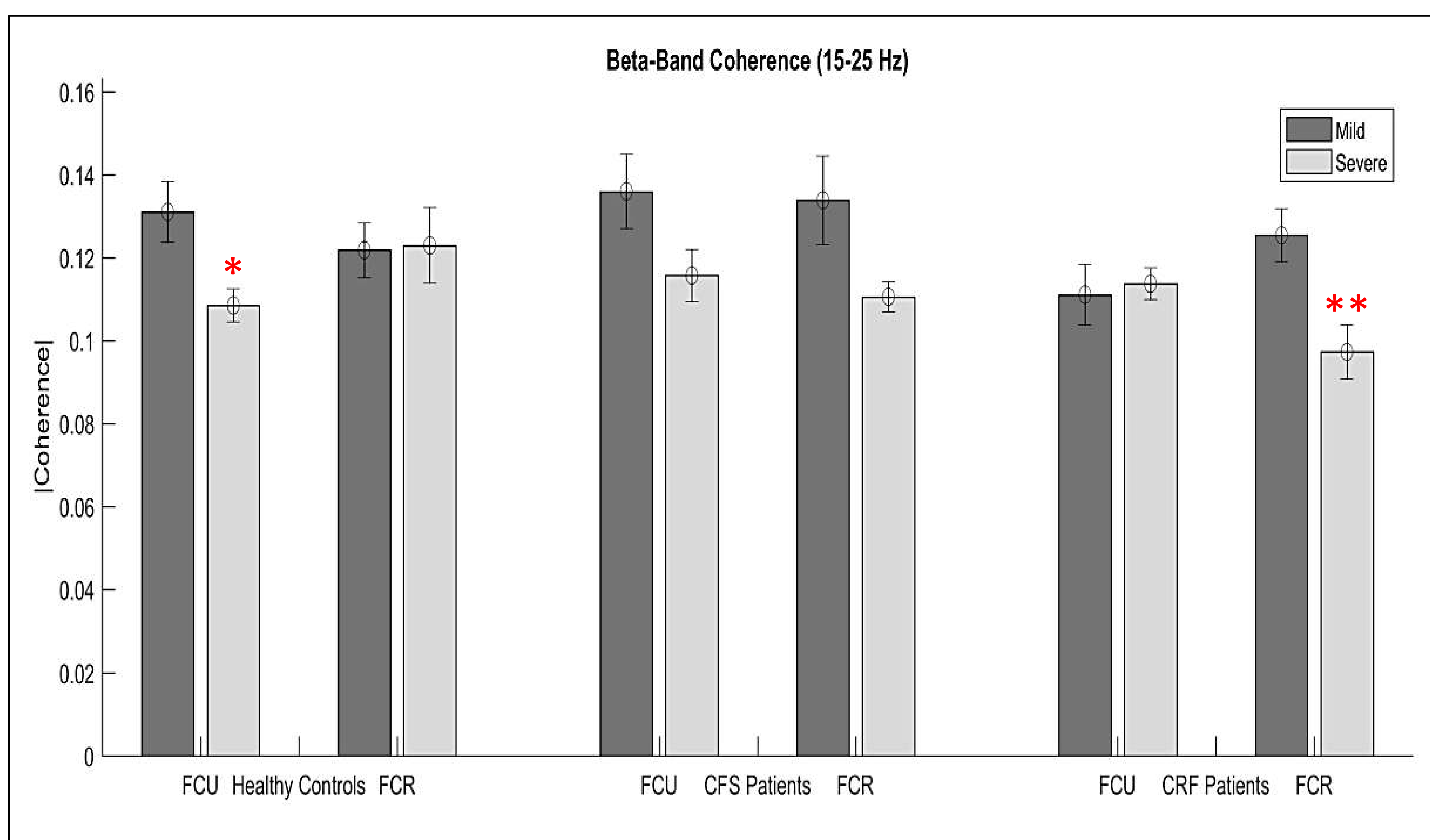

Figure 2: Lower ßeta-band coherence changes over contralateral motor cortex for both muscles at each fatigue stage in al three cohorts. $\left({ }^{\star} \mathrm{P}<0.05,{ }^{\star \star} \mathrm{P}<0.001\right)$

\section{CONCLUSIONS}

1. CRF was associated with weakened corticomuscular coherence.

2. This suggests central mechanisms may contribute to CRF and CFS with associated performance impairment.

3. Interventions to improve coherence may reduce fatigue in CRF and CFS.

4. $\mathrm{CRF}$ is related to physiological alterations and is present at diagnosis before treatment 